\title{
POSTURA DE LA SUPREMA CORTE DE JUSTICIA DE LA NACIÓN EN RELACIÓN CON LA PRESCRIPCIÓN DEL CRIMEN DE GENOCIDIO*
}

\author{
Ponente: ministro Juan N. Silva Meza \\ Secretario: Jaime Flores Cruz
}

\section{SÍNTESIS}

El veintidós de julio de dos mil cuatro, el Agente del Ministerio Publico de la Federación adscrito a la Oficina del Fiscal Especial para la Atención de Hechos Probablemente Constitutivos de Delitos Federales Cometidos Directa o Indirectamente por Servidores Públicos en Contra de Personas Vinculadas con Movimientos Sociales y Políticos del Pasado, una vez integrada la averiguación previa, ejerció acción penal en contra de Luis Echeverría Álvarez, Mario Augusto José Moya y Palencia, Luis de la Barreda Moreno, Miguel Nazar Haro, José Antonio González Aleu, Manuel Díaz Escobar Figueroa (a) "el Maestro”, Rafael Delgado Reyes (a) "el Rafles", Sergio San Martín Arrieta (a) "el Watusi", Alejandro Eleazar Barrón Rivera (a) "el Pichín”, Sergio Mario Romero Ramírez (a) "el Fish" y Victor Manuel Flores Reyes (a) "el Coreano", como probables responsables de la comisión del delito de Genocidio, previsto en el artículo 149 bis del Código Penal para el Distrito y Territorios Federales en Materia de Fuero común y para toda la República en Materia de Fuero Federal, vigente en mil novecientos setenta y uno.

b) Del asunto correspondió conocer, por razón de turno, al Juez Segundo de Distrito de Procesos Penales Federales en el Distrito Federal, quien mediante acuerdo de veintitrés de julio de dos mil cuatro, radicó el asunto registrándose con el número 114/2004.

c) En proveído de veinticuatro de julio de dos mil cuatro, el Juez de Distrito del conocimiento, determinó declarar extinguida la acción penal respecto del delito de genocidio, a favor de los inculpados, decretando el sobreseimiento de la causa penal.

\footnotetext{
* Recurso de Apelación 1/2004-PS.
} 
d) Inconformes con la determinación anterior, el Ministerio Público de la Federación, Agente Investigador y el adscrito al Juzgado de referencia, interpusieron recurso de apelación, mediante sendos escritos presentados el veintiséis y veintisiete de julio de dos mil cuatro.

e) En acuerdo de veintisiete de julio de dos mil cuatro, el Juez de Distrito del conocimiento, tuvo por admitidos dichos recursos en el efecto devolutivo; asimismo ordenó remitir los autos al Tribunal Unitario del Primer Circuito en turno, en diverso acuerdo de veintinueve del mes y año en cita.

f) De los recursos de apelación, correspondió conocer al Quinto Tribunal Unitario en Materia Penal del Primer Circuito, quien mediante acuerdo de seis de agosto de dos mil cuatro, ordenó registrar el toca penal con el número $415 / 2004$.

g) Señalándose las diez horas con quince minutos del día dieciocho de agosto de dos mil cuatro, para que se verificara la audiencia de vista, el Ministerio Público de la Federación Comisionado en la Oficina del Fiscal Especial para la Atención de Hechos Probablemente Constitutivos de Delitos Federales Cometidos Directa o Indirectamente por Servidores Públicos en Contra de Personas Vinculadas con Movimientos Sociales y Políticos del Pasado, mediante escrito presentado el dieciocho de ese mismo mes y año, formuló agravios, adhiriéndose a los mismos el Agente del Ministerio Público de la Federación adscrito, tal y como lo manifestó en el escrito presentado en la fecha precitada.

h) Una vez celebrada la audiencia pública y estando pendiente el dictado de la resolución respectiva, el Procurador General de la República, por oficio PGR/672/2004, presentado el veinticinco de agosto de dos mil cuatro en la Oficina de Certificación Judicial y Correspondencia de esta Suprema Corte de Justicia de la Nación, solicitó que la Primera Sala ejerza facultad de atracción para conocer del recurso de apelación de merito, con fundamento en los artículos 105, fracción 111, de la Constitución General de la República; 10, fracción Xl, 21, fracción I, 25, fracción V y 141, tercer párrafo, de la Ley Orgánica del Poder Judicial de la Federación.

i) Esta Primera Sala de la Suprema Corte de Justicia de la Nación, el trece de octubre de dos mil cuatro, resolvió 1 ejercer la facultad de atracción para conocer de los recursos de apelación interpuestos por los Agentes del Ministerio Público de la Federación (páginas 281 a 284).

Recurrentes: Agente del Ministerio Público de la Federación Comisionado en la Oficina del Fiscal Especial para la Atención de Hechos Probablemente Constitutivos de Delitos Federales Cometidos Directa o Indirectamente por Servidores Públicos en Contra de Personas Vinculadas con Movimientos Sociales y Políticos del Pasado y del Agente del 
Ministerio Público de la Federación adscrito al Juzgado Segundo de Distrito de Procesos Penales Federales en el Distrito Federal (página 59).

En la consulta se propone:

En las consideraciones:

A) De conformidad con el artículo I, inciso b), de la Convención sobre la Imprescriptibilidad de los Crímenes de Guerra y de los Crímenes de Lesa Humanidad, son imprescriptibles los delitos de lesa humanidad, según la definición dada en el Estatuto del Tribunal Militar Internacional de Nüremberg.

La Convención aludida, de acuerdo a lo transcrito, fue sometida a la consideración de la Cámara de Senadores, del Congreso de la Unión, junto con una Declaración Interpretativa, en la que esencialmente se expuso, que con fundamento en el articulo 14 de la Constitución General de la República, el gobierno de nuestro país entenderá que únicamente considerará imprescriptibles los crímenes que consagra la Convención, cometidos con posterioridad a su entrada en vigor para México.

Ahora bien, resulta conveniente señalar que la "figura jurídica de la reserva expresa ha sido reconocida por la Convención de Viena sobre Derecho de los Tratados para cuando una norma internacional contenida en un tratado en el que sea parte un Estado, afecte de manera manifiesta normas fundamentales de su derecho interno, pueda alegar tal circunstancia como fundamento de su no consentimiento y, por tanto, su inaplicación en lo conducente".

En cuanto a la Declaración Interpretativa, debe decirse que de "acuerdo a la doctrina, la interpretación del tratado tiene como finalidad determinar la forma en que deberán ser aplicadas las normas jurídicas contenidas en el mismo y aclarar sus ambigüedades" (controversia constitucional 33/2002).

En atención a lo relatado, lo expuesto por los Estados Unidos Mexicanos en relación a la Convención sobre la Imprescriptibilidad de los Crímenes de Guerra y de los Crímenes de Lesa Humanidad, es una Declaración Interpretativa, en virtud de que se acepta la imprescriptibilidad del delito de genocidio, condicionando su aplicación a que se haya cometido con posterioridad a la entrada en vigor de dicho instrumento internacional en nuestro país.

El problema que surge al respecto, es si puede dejarse de aplicar el contenido de una Declaración Interpretativa realizada por un país, cuando va en contra de la finalidad principal de una Convención, tomando en cuenta para ello el derecho internacional público, el cual puede ser entendido como el conjunto de normas que regulan las relaciones entre Estados soberanos y con la comunidad internacional. 
En el caso, la referida Convención y otros instrumentos internacionales que abordan el tema sobre la interpretación de los tratados, a los cuales alude la parte recurrente en su escrito de expresión de agravios, conducen a la conclusión de que el delito de genocidio es imprescriptible, cualquiera que sea la fecha en que se haya cometido; sin embargo, la Declaración Interpretativa realizada en los términos apuntados, parece limitar los alcances de esa voluntad internacional.

Conviene recordar, que una vez que las partes negociadoras firman el tratado o canjean instrumentos que lo constituyan, quedan obligadas a abstenerse de cualquier acto que frustre el objeto y fin del tratado, sin importar que se encuentre pendiente de ratificación, aceptación o aprobación, pues así deriva de lo dispuesto por los artículos 11 y 18 de la Convención de Viena sobre el Derecho de los Tratados, es decir, que la sola firma "ad referéndum" del tratado o el intercambio de instrumentos que la constituyan produce las consecuencias jurídicas señaladas.

Ante este panorama, al constituir la Declaración Interpretativa, eso, una interpretación de la Convención sobre la Imprescriptibilidad de los Crímenes de Guerra y de los crímenes de Lesa Humanidad, y no una reserva, esta Suprema Corte de Justicia de la Nación, no queda constreñida a observar o a seguir dicha interpretación, sino que puede, como máximo intérprete de la Constitución (intérprete definitivo de la Ley Fundamental) y de las leyes que de ella emanan, realizar la propia, y que sea acorde con los compromisos adquiridos por nuestro país a nivel internacional, aspecto que también tiene su sustento en la propia Convención aludida como se expondrá más adelante (páginas 153 a 156).

B) En atención a lo relatado, la interpretación de mérito, debe atender a los postulados contemplados en la propia Convención sobre la Imprescriptibilidad de los Crímenes de Guerra y de los Crímenes de Lesa Humanidad; asimismo, como no existen reglas al respecto en la Constitución General de la República y en la Ley sobre la Celebración de Tratados, también se atenderá a lo que dispone la Convención de Viena sobre el Derecho de los Tratados.

Lo expuesto, permite inferir que los Estados Parte, observando que en ninguna declaración solemne, instrumento o convención para el enjuiciamiento y castigo de los crímenes de guerra y de los crímenes de lesa humanidad se ha previsto limitación en el tiempo; asimismo, que la aplicación a esta clase de crímenes de las normas de derecho interno relativas a la prescripción de los delitos ordinarios suscita grave preocupación en la opinión pública mundial, pues impide el enjuiciamiento y castigo de las personas responsables de esos crímenes; reconocieron que es necesario y oportuno afirmar en derecho internacional, por medio de la Convención de referencia, el principio de la imprescriptibilidad de los 
crímenes de guerra y de los crímenes de lesa humanidad y asegurar su aplicación universal.

Para cumplir con el objeto y fin de dicho instrumento internacional, destaca lo que se establece en el articulo IV, en el sentido de que los Estados Parte, se comprometen a adoptar, con arreglo a sus respectivos procedimientos constitucionales, las medidas legislativas o de otra indole que fueran necesarias para que la prescripción de la acción penal o de la pena, establecida por ley o de otro modo, no se aplique a los crímenes mencionados.

Lo anterior, significa que los Estados Parte se comprometieron a adoptar las medidas necesarias para que la prescripción establecida por ley o de otro modo, no se aplique a dichos crímenes; medidas que pueden llevarse a cabo de la forma siguiente:

a) Con arreglo a sus respectivos procedimientos constitucionales, las medidas legislativas o,

b) De otra indole.

De esta manera, cuando el instrumento internacional que se analiza, acepta, como medida para que la figura jurídica de la prescripción de la acción penal o de la pena no se aplique a dichos crímenes, a la de índole diferente a la legislativa, puede comprender dentro de la misma a la labor interpretativa, tanto de normas contempladas en la Constitución Política de los Estados Unidos Mexicanos, así como las previstas en las leyes secundarias.

En estas condiciones, esta Primera Sala de la Suprema Corte de Justicia de la Nación, ante los compromisos asumidos por nuestro país, como Estado soberano, con la comunidad internacional, considera que para que se cumpla con toda puntualidad el objeto y fin de la Convención sobre la Imprescriptibilidad de los Crímenes de Guerra y los Crímenes de Lesa Humanidad, utilizando la labor interpretativa, no estando supeditada a alguna otra, como medio de diversa índole al legislativo de acuerdo a dicho instrumento internacional, procede a fijar los alcances del articulo 14 de la Constitución Política de los Estados Unidos Mexicanos, específicamente en relación con el principio de irretroactividad de la ley (páginas 160 a 169).

C) En estas condiciones, no obstante que este Alto Tribunal ha interpretado el principio de irretroactividad, en los términos que esencialmente quedaron relatados, la asunción de compromisos con la comunidad internacional por parte de los Estados Unidos Mexicanos, impone que se lleve a cabo una interpretación que ahora sea acorde al objeto y finalidades que persigue la Convención sobre la Imprescriptibilidad de los Crímenes de Guerra y de los Crímenes de Lesa Humanidad, que por 
disposición del articulo 133 de la Constitución General de la República, forma parte de nuestro universo normativo.

Partiendo de la base de una interpretación progresiva (consistente en adaptar los textos constitucionales a la dinámica de la comunidad internacional del presente) y sistemática, debe señalarse que si bien el principio de irretroactividad de la ley, consagrado en el articulo 14 constitucional, fue establecido para la protección del gobernado en contra del legislador y de autoridades, que en ejercicio de sus facultades generan actos retroactivos en su perjuicio, la incorporación de normas de naturaleza internacional a nuestro derecho interno, las conductas que lesionan de forma trascendente los valores fundamentales de la sociedad mundial y la preocupación que existe para que las personas que llevaron a cabo esas conductas sean castigados por ser penalmente reprochable su conducta, genera que el citado principio no deba ser entendido en esos mismos términos.

El reconocimiento de los derechos fundamentales del individuo en la Constitución Política de los Estados Unidos Mexicanos, implica también el reconocimiento de los derechos fundamentales de la sociedad considerada en su conjunto y como parte conformadora de la humanidad; de esta manera, del principio de irretroactividad se vislumbra un equilibrio entre los derechos fundamentales del individuo a quien se le atribuye la comisión de un delito y los derechos fundamentales que corresponden a la sociedad.

Así, puede afirmarse que el Poder Constituyente al consagrar en el articulo 14 de la Constitución General de la República el principio de irretroactividad, no lo hizo con la finalidad de que las conductas que afectan gravemente a la humanidad, quedaran impunes, en virtud de que en todo el contexto normativo constitucional se encuentra, como una de sus bases sustentadoras, el diverso principio de justicia.

El principio de irretroactividad de la ley, protege, en el ámbito penal, a la persona a quien se le atribuye la comisión de un delito, pero ello no significa que las personas que dañan en grado superlativo a la sociedad, mancillando sus valores más preciados, puedan, a través de dicho principio, quedar al margen de la acción de la justicia.

En estas condiciones, el principio de irretroactividad consagrado en el articulo 14 constitucional, no es aplicable al Tratado Internacional, como lo es la Convención sobre la Imprescriptibilidad de los Crímenes de Guerra y de los Crímenes de Lesa Humanidad, en la forma en que tradicionalmente se venia haciendo respecto de las leyes de origen nacional, independientemente de la naturaleza que le pueda corresponder a la figura jurídica de la prescripción (páginas 171 a 173). 
D) A lo anterior, debe agregarse que si bien en diversos instrumentos internacionales se contempla el principio de irretroactividad de la ley, es también en un diverso instrumento internacional, como lo es la Convención sobre la Imprescriptibilidad de los Crímenes de Guerra y de los Crímenes de Lesa Humanidad, en donde ese principio, por voluntad soberana de los Estados Parte, encuentra su inaplicabilidad a casos como son los delitos de lesa humanidad, dentro de los que se encuentra el delito de genocidio.

La anterior interpretación es acorde con el objeto y fin de la Convención de mérito, que es el de establecer la imprescriptibilidad de los crímenes de guerra y de los crímenes de lesa humanidad y asegurar su aplicación universal.

En su oportunidad quedó apuntado, de acuerdo a dicho instrumento internacional, que los crímenes de lesa humanidad, entre los cuales se contempla al delito de genocidio, son imprescriptibles según la definición dada en el Estatuto del Tribunal Militar Internacional de Nüremberg (páginas 174 y 175).

E) Como puede advertirse, independientemente del reconocimiento del principio de no retroactividad de la ley, atendiendo a la circunstancia de que existen delitos que dañan en grado superior que otros a la sociedad y que trascienden fuera de las fronteras de un país, se optó por instituir, en un instrumento internacional, la imprescriptibilidad de diversos delitos denominados de lesa humanidad, incluyendo dentro de los mismos al delito de genocidio.

La Convención sobre la Imprescriptibilidad de los Crímenes de Guerra y de los Crímenes de Lesa Humanidad, no tuvo la intención de suprimir el principio de no retroactividad de la ley, sino que siguiendo el principio de justicia, se sustentó en el argumento de que los delitos que lesionan a la humanidad permanecen incólumes ante el indefectible paso del tiempo, con abstracción total de la fecha en que se haya ratificado o entrando en vigor ese instrumento internacional, en virtud de que cierta clase de delitos, como el delito de genocidio, cuando tiene su aparición en el mundo fáctico, genera simultáneamente su perdurabilidad para ser reprochado jurídicamente por los órganos facultados para ello (páginas 176 y 177$)$.

F) En otro orden de ideas, no obstante que la figura jurídica de la prescripción tiene como fundamentos la de considerarse contraria al interés social, mantener indefinidamente una imputación delictuosa, que se debilitan las pruebas con el transcurso del tiempo, que la sustracción de la acción del Estado efectuada por el delincuente es de por si suficiente sufrimiento y que, por último, el daño mediato y la razón política de la pena dejan de existir; en el caso de los delitos de lesa humanidad, no 
tienen aplicación dichos fundamentos, en virtud de que los Estados Parte, en ejercicio de su soberanía y atendiendo a bienes jurídicos supraindividuales, externaron su voluntad, misma que quedó reflejada en la Convención sobre la Imprescriptibilidad de los Crímenes de Guerra y de los Crímenes de Lesa Humanidad, en donde la medida de tiempo que se fija en el Código Penal de nuestro país para la prescripción de la acción penal o de la pena, desapareció, dejando intocado el delito de genocidio para ser jurídicamente reprochable a quienes desplegaron la conducta respectiva, cualquiera que sea la fecha en que se haya cometido (páginas 179 y 180$)$.

G) La interpretación realizada, así como el instrumento internacional sujeto a análisis, es acorde con lo establecido en el articulo 15 de la Constitución Política de los Estados Unidos Mexicanos, el que en su parte conducente dispone que: "No se autoriza la celebración... ni de convenios o tratados en virtud de los que se alteren las garantías y derechos establecidos por esta Constitución para el hombre y el ciudadano"; ello en razón de que la Convención sobre la Imprescriptibilidad de los Crímenes de Guerra y de los Crímenes de Lesa Humanidad, tiene como objeto y fin el establecer la imprescriptibilidad de los crímenes de guerra y de los crímenes de lesa humanidad y asegurar su aplicación universal, siendo que el delito de genocidio protege la existencia de determinados grupos humanos, por lo que se está en presencia de un bien jurídico supra- individual, cuyo titular no es la persona física sino el grupo como colectividad.

H) En conclusión, la acción penal respecto del delito de genocidio por el que ejerció acción penal el Agente del Ministerio Público de la Federación adscrito a la Oficina del Fiscal Especial para la Atención de Hechos Probablemente Constitutivos de Delitos Federales Cometidos Directa o Indirectamente por Servidores Públicos en contra de Personas Vinculadas con Movimientos Sociales y Políticos del Pasado, asunto que se radicó y fue registrado con el número 11412004 del índice del Juzgado Segundo de Distrito de Procesos Penales Federales en el Distrito Federal, no se ha extinguido, de acuerdo a lo expuesto en los párrafos precedentes (páginas 180 y 181).

I) En atención a los razonamientos anteriores y en términos de los considerandos séptimo y octavo de la presente resolución, lo procedente es revocar el auto recurrido de fecha veinticuatro de julio de dos mil cuatro dictado por el Juez Segundo de Distrito de Procesos Penales Federales en el Distrito Federal, por el que declaró extinguida la acción penal ejercida por la Representación Social Federal, en contra de Luis Echeverría Álvarez, Mario Augusto José Moya y Palencia, Luis de la Barreda Moreno, Miguel Nazar Haro, José Antonio González Aleu, Manuel Díaz 
Escobar Figueroa (a) "el Maestro", Rafael Delgado Reyes (A) "el Rafles", Sergio San Martín Arrieta (A) "el Watusi”, Alejandro Eleazar Barrón Rivera (A) "el Pichín", Sergio Mario Romero Ramirez (A) "el Fish" y Victor Manuel Flores Reyes (A) "el Coreano", por su probable responsabilidad en la comisión del delito de genocidio y que sobresee la causa penal, lo que imposibilitó legalmente al Juez de origen para analizar los requisitos constitucionales de probable responsabilidad y cuerpo del delito, para el efecto de que en términos de la presente resolución, el Tribunal Unitario de Circuito del conocimiento aborde los extremos marcados en el articulo 16 constitucional respecto de la probable responsabilidad y cuerpo del delito (páginas 181 y 182).

\section{Comentario}

Lo anterior trascrito forma parte de la ponencia del ministro Juan N. Silva Meza que fue rechazada en sesión pública ordinaria, celebrada el miércoles nueve de marzo de dos mil cinco, lo que trajo por resultado la decisión de que la Convención sobre la Imprescriptibilidad de los Crímenes de Guerra y de los Crímenes de Lesa Humanidad de 1968 no se aplica en forma retroactiva, lo que da paso a la prescripción de los crímenes cometidos en el caso de que se trata.

El asunto de que se trata tiene una singular importancia no sólo jurídica, sino política, pues se trata de hechos ocurridos en 1971, el 10 de junio, bajo el gobierno de Luis Echeverría Álvarez, cuando fuerzas de choque del gobierno, denominadas "halcones", agredieron a una manifestación estudiantil, resultando heridos y muertos varias decenas de jóvenes, parte de un movimiento estudiantil que el 2 de octubre de 1968 fue brutalmente reprimida por el gobierno del presidente Gustavo Díaz Ordaz.

El asunto desde la perspectiva jurídica tiene un fuente contenido de derecho internacional que tiene que ver con la interpretación de los tratados internacionales frente de la Constitución y en especial de los tratados internacionales de derechos humanos, los conceptos de jus cogens y de las reservas de los tratados, así como de fuentes de derecho internacional, 
concretamente de la costumbre internacional. Lo que al parecer fue un "platillo fuerte" de derecho internacional que no alcanzaron a digerir algunos de los ministros.

Ahora resta esperar los comentarios doctrinales, que seguro ya se preparan.

Manuel BECERRA RAMÍREZ* 